\title{
Test Results for a Non-Toxic Dual Thrust Reaction Control Engine
}

\author{
Philip J. Robinson ${ }^{*}$.and Eric M. Veith ${ }^{\dagger}$ \\ Aerojet, Sacramento, CA, 95813 \\ Alicia A. Turpin. ${ }^{\ddagger}$ \\ NASA Marshall Space Flight Center, Huntsville, AL, 35812
}

\begin{abstract}
A non-toxic, dual thrust reaction control engine (RCE) was successfully tested over a broad range of operating conditions at the Aerojet Sacramento facility. The RCE utilized LOX/Ethanol propellants; and was tested in steady state and pulsing modes at 25-lbf thrust (vernier) and at 870-lbf thrust (primary). Steady state vernier tests varied chamber pressure $(\mathrm{Pc})$ from 0.78 to $5.96 \mathrm{psia}$, and mixture ratio (MR) from 0.73 to 1.82 , while primary steady state tests varied Pc from 103 to 179 psia and MR from 1.33 to 1.76 . Pulsing tests explored EPW from 0.080 to 10 seconds and DC from 5 to 50 percent at both thrust levels. Vernier testing accumulated a total of 6,670 seconds of firing time, and 7,215 pulses, and primary testing accumulated a total of 2,060 seconds of firing time and 3,646 pulses.
\end{abstract}

$$
\begin{array}{ll}
D C & =\text { duty cycle for pulsing } \\
\text { EPW } & =\text { electrical pulse width } \\
F & =\text { thrust } \\
F v a c & =\text { vacuum corrected thrust } \\
I s p & =\text { specific impulse } \\
I s p, v a c & =\text { vacuum specific impulse } \\
l b f & =\text { pounds force } \\
l b m & =\text { pounds mass } \\
L O X & =\text { liquid oxygen }
\end{array}
$$

\section{Nomenclature}

$\begin{array}{ll}M R & =\text { mixture ratio } \\ P C & =\text { chamber pressure } \\ P C A V & =\text { main chamber pressure } \\ \text { PCIgn } & =\text { igniter chamber pressure } \\ \text { STE } & =\text { special test equipment } \\ T C H A M & =\text { chamber temperature } \\ \text { TINJF } & =\text { injector face temperature } \\ \varepsilon & =\text { nozzle expansion ratio }\end{array}$

\section{Introduction}

The National Aeronautics and Space Administration's (NASA) George C. Marshall Space Flight Center (MSFC) contracted with Aerojet to develop and expand the technologies necessary to support non-toxic, on-orbit auxiliary propulsion system (APS) needs for future space vehicle applications. Contract NAS8-01109 was issued to Aerojet to develop a dual thrust Reaction Control Engine (RCE) that utilizes oxygen and ethanol as the propellants. For the purposes of this contract, thrust levels of $870 \mathrm{lbf}$ and $25 \mathrm{lbf}$ were selected for the primary and the vernier operating modes, respectively, reflecting the current Space Shuttle Orbiter APS thrust levels.

The Aerojet contract was divided into three separately funded phases: Basic, Option 1 and Option 1 Extension. The Basic phase of the contract was comprised of testing the Aerojet owned Kistler K-1 Orbital Maneuvering Engine (OME) in vernier and primary modes with the aid of special test equipment (STE) designed on

\footnotetext{
* Technical Principal, Mechanical Engineering, Dept. 5272/BIdg.20-019, AIAA Senior Member.

† Program Manager, Advanced Space Propulsion, Dept. 4370/Bldg. 20-001, AIAA Senior Member.

‡ Propulsion Engineer, Spacecraft Propulsion Systems Branch, Mail Stop ER23, AIAA Non-Member.
}

PRA-SA-NASA MSFC \#052-05. 11 July 2005 
the contract. In addition to this testing, the Basic phase initiated development of quick response LOX and ethanol direct-acting solenoid valves to meet the 0.080 -second EPW requirement for Option 1 testing. At the beginning of Option 1, a LOX igniter was developed to support a liquid-liquid system, and was verified through extensive testing. After the LOX igniter development, Option 1 utilized the hot fire test data from the Basic phase to calibrate the analytical performance and thermal models required to support the design, fabrication, and test of an integrated dual thrust RCE demonstration engine, which is the topic of this paper. The final phase of the contract, the Option 1 Extension, used the Option 1 test data to make additional small iterations to the RCE design, from which three deliverable prototype thruster assemblies were fabricated, acceptance tested and delivered to the NASA White Sands Test Facility (WSTF) in New Mexico. These three engine assemblies were installed on the NASA on-orbit APS test article in preparation for system level hot-fire testing planned for the latter part of 2005.

\section{A. Background}

The feasibility of the dual thrust RCE concept was first demonstrated by testing performed at the NASA WSTF. ${ }^{1}$ A 600-lbf GOX/Ethanol Reaction Control System (RCS) workhorse thruster, developed by Aerojet in the 1980's for the NASA Johnson Space Center (JSC), was utilized for this dual thrust feasibility testing at WSTF. Some hardware modifications were required, as the feasibility testing intended to simulate operation of the current Space Shuttle 25lbf vernier reaction control subsystem (VRCS) engine. These modifications were made to the RCS thruster hardware to permit igniter operation in conjunction with a reduced auxiliary GOX flow through the injector face. A corresponding reduced ethanol boundary layer cooling (BLC) flow was also utilized to achieve the total flow rate required for 25 -lbf operation. The workhorse RCS thruster incorporated a center-mounted GOX/Ethanol sparkinitiated torch igniter. These hardware modifications successfully simulated the function of the current Space Shuttle 25-lbf (VRCS) engine for tests of short duration ( 30 seconds).

The Basic phase of the Aerojet contract continued in the path of the NASA JSC sponsored WSTF testing described above, utilizing the existing Aerojet owned Kistler K-1 OME which was designed for 870-lbf thrust and 150 psia chamber pressure (Pc). Although the K-1 OME hardware had undergone some previous testing in steady state mode, as well as limited testing in pulse mode ${ }^{2}$, it was necessary to design and fabricate some special test equipment (STE) to enable the K-1 OME to operate at the $25 \mathrm{lbf}$ thrust level. As a result, the K-1 OME successfully completed both a 25-lbf vernier test series (with STE) and an 870-lbf primary test series at the Aerojet Sacramento facility during the Basic phase. ${ }^{3}$ This testing extended the steady state vernier test duration from the approximately 30 seconds obtained at WSTF to $422 \mathrm{sec}$, as well as demonstrating some vernier pulse mode operation. In addition, the primary mode testing evaluated the effects of varying chamber pressure (Pc) and mixture ratio (MR), as well as pulse mode operation. The performance and thermal data obtained from the Basic phase testing with the K-1 OME hardware provided the foundation for calibrating the analytical performance and thermal models required to support the Option 1 phase design, fabrication and test of an integrated dual thrust RCE demonstration engine.

\section{B. Option 1 Design Approach}

The design of the Option 1 demonstration engine was based heavily on the analysis of the thermal data obtained from the Basic test program. The thermal data consisted of direct temperature measurements made by thermocouples attached in three rows along the outer wall of the combustion chamber. Analysis of this thermal data allowed the recovery temperatures and the heat transfer coefficients to be inferred for the vernier and the primary operating modes. An Aerojet predictive thermal model (SCALE) incorporated these inferred recovery temperatures and heat transfer coefficients to establish the design requirements for the Option 1 demonstration engine.

A spark-initiated torch igniter was mounted in the center of the injector, similar to the K-1 OME, but unlike the K-1 OME, the Option 1 igniter was LOX/Ethanol, rather than GOX/Ethanol. The LOX/Ethanol igniter was developed on the same NASA MSFC contract prior to development of the integrated dual thrust RCE demonstration engine. Extensive ignition testing (124 tests) provided four key results: (1) verified reliable and repeatable ignition for oxygen inlet temperatures ranging from $210-486^{\circ} \mathrm{R}$ (LOX to GOX); (2) pulsed at 0.080 -second EPW and 50 percent duty cycle (DC) for 400 pulses; (3) ran long steady state duration tests of up to 720 seconds; (4) accumulated over 20,000 seconds of operational time.

\section{Option 1 Design Parameters}

\section{Primary Mode Design Parameters}

The Option 1 primary mode design parameters underwent minimal adjustments from the Kistler K-1 OME design point. Specifically, the thrust level of $870 \mathrm{lbf}$, the Pc of $150 \mathrm{psia}$, and the MR of 1.5 were maintained, along with the amount of fuel used as boundary layer cooling, or fuel film cooling (FFC). Additional injector core elements were added. The thrust level of $870 \mathrm{lbf}$ was established for a nozzle area ratio of $22: 1$, consistent with the

2

American Institute of Aeronautics and Astronautics 
current Space Shuttle 870-lbf primary reaction control subsystem (PRCS) engine. However, the actual Option 1 test hardware utilized a 15-degree conical nozzle truncated to 3:1 to facilitate testing at ambient atmospheric pressure. Typical vacuum corrected thrust for the engine exhausting into ambient atmospheric pressure at nominal operating conditions ( $\mathrm{Pc}$ of $150 \mathrm{psia}$ and MR of 1.5) was $762 \mathrm{lbf}$. The primary mode design parameters are summarized in Table I.

\section{Vernier Mode Design Parameters}

The vernier mode design parameters were modified from the Basic test hardware (K-1 OME with STE). As the combustion chamber throat is sized for operating in the primary mode at a Pc of 150 psia, the resulting vernier operating mode $\mathrm{Pc}$ is approximately 5 psia. Based on a performance analysis that evaluated the Basic vernier test data, it turns out that the kinetics losses are substantially higher than typically encountered, and the optimum MR for maximum performance is 1.35 , rather than 1.5 as in the case of the primary mode.

The vernier injector elements were incorporated into the main injector, rather than any STE, and were placed in-between the primary mode injector elements. The addition of the vernier elements necessitated increasing the injector face area slightly to accommodate packaging of both vernier and primary elements within the same injector. Therefore, the combustion chamber diameter was increased to match the increased injector diameter, which increased the chamber contraction ratio. The vernier mode design parameters are also summarized in Table I.

Table 1. Summary of Option 1 Design Parameters

\begin{tabular}{|l|c|c|}
\hline \multicolumn{1}{|c|}{ Design Parameter } & Primary Mode & Vernier Mode \\
\hline \hline Thrust, lbf $($ for $\varepsilon=22: 1)$ & 870 & 25 \\
\hline Chamber Pressure, psia & 150 & 4.8 \\
\hline Mixture Ratio, O/F & 1.50 & 1.35 \\
\hline Nozzle Expansion Ratio & \multicolumn{2}{|c|}{22 (design)/3 (test) } \\
\hline
\end{tabular}

\section{Option 1 Hardware Description}

The Option 1 test hardware of Fig. 1 consisted of an igniter assembly, igniter valves, an injector assembly, injector valves and a thrust chamber. All of the Option 1 engine components were designed and developed under the NASA MSFC dual thrust RCE contract. In addition to the engine components, a spark exciter was also developed to provide the necessary voltage and energy to the igniter spark plug. The spark exciter was not depicted in Fig. 1. The engine cross sections depicted in Fig. 2 represented two mutually perpendicular longitudinal planes: one taken through the igniter/vernier valves and the other through the injector/primary valves.

\section{Igniter Assembly}

The Option 1 igniter assembly was a spark-initiated torch type, designed to operate on LOX/Ethanol. Previous igniter designs were typically GOX/Ethanol, e.g. the Aerojet K-1 igniter, because the gaseous oxygen and ethanol mixtures ignited more readily. The spark-initiated torch type igniter design was selected because it was well characterized through extensive testing on a variety of programs ${ }^{5-6}$ spanning 30 years, and specifically for GOX/Ethanol on NASA Contract NAS9-16639 in the 1980's. ${ }^{7}$ The requirement for a LOX/Ethanol igniter was stipulated in the contract so that the dual thrust RCE would be compatible with a LOX-based feed system, thereby
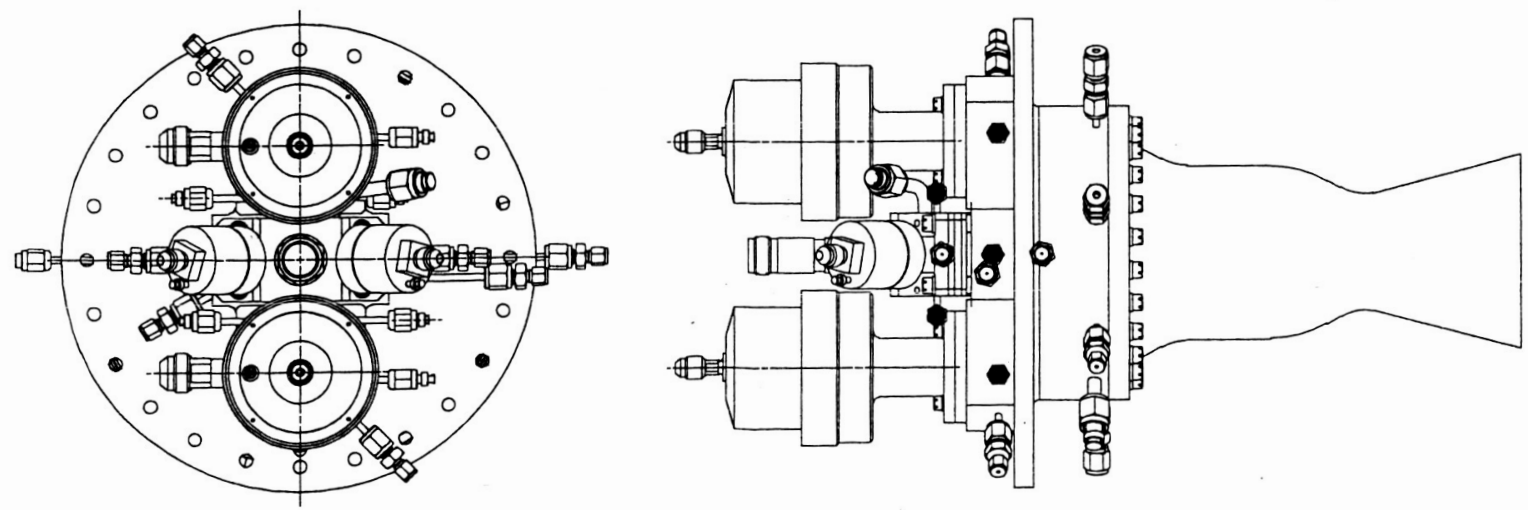

Figure 1. Option 1 Dual Thrust Demonstration Hardware 
not requiring separate GOX storage tanks, or a complicated LOX gasification subsystem for a future flight configuration. Consequently, the K-1 GOX/Ethanol igniter was modified for use with LOX/Ethanol, and its operation successfully verified through a separate LOX ignition demonstration test series, which was completed in the early part of the Option 1 effort prior to the development of the integrated dual thrust demonstration engine.
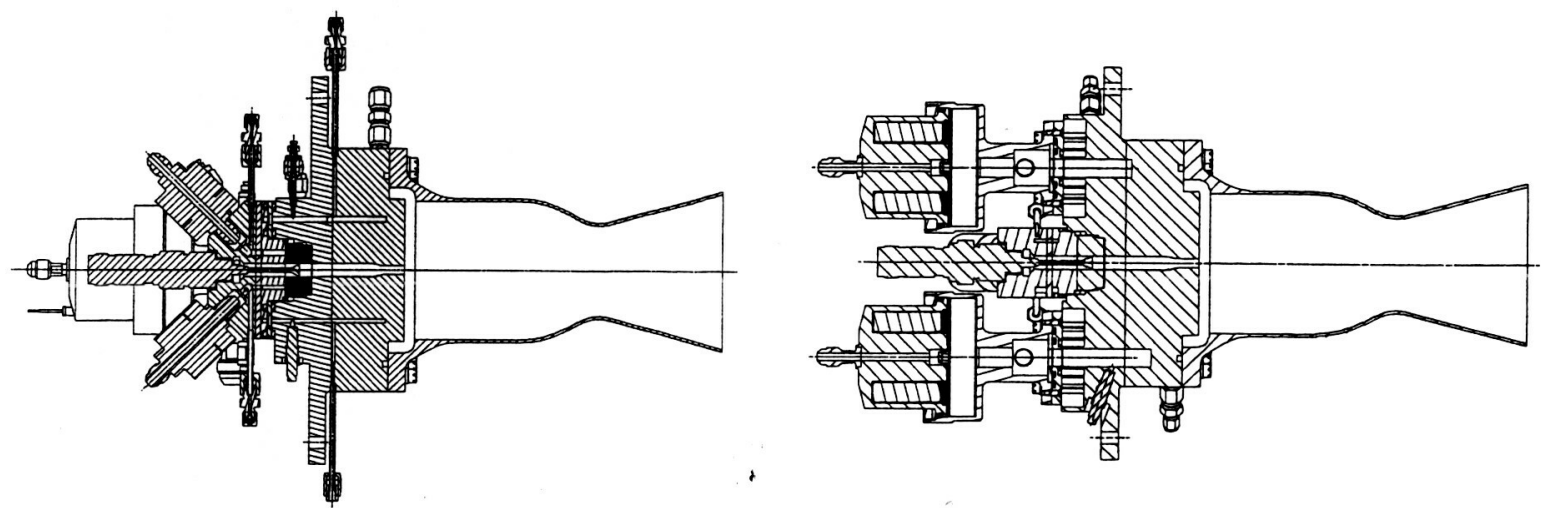

Figure 2. Engine Cross Sections Taken through the Igniter/Vernier Valves and the Injector/Primary Valves

The igniter assembly consisted of individually photo-chemically machined nickel platelets that were diffusion bonded to a machined Inconel igniter body. The igniter body provided for direct mounting of the igniter valves and the spark plug, as well as for instrumentation ports for measuring igniter and vernier manifold pressures and temperatures, and the igniter chamber pressure. The igniter assembly bolted directly to the injector assembly, a cross section of which is depicted in Fig. 3.

The igniter by itself provided approximately $5.6 \mathrm{lbf}$ of thrust, which meant the remainder of the vernier oxidizer and fuel flow required to attain 25 -lbf thrust was split off to the vernier circuits embedded in the main injector. The split between igniter flow and injector vernier flow occurred within the igniter assembly, as shown in the vernier propellant flow diagram of Fig. 4. The engine was also operated in igniter-only mode by installing an injector vernier circuit blanking plate between the igniter and the injector during assembly.

\section{Injector Assembly}

The injector was comprised of individually photochemically machined nickel platelets that were diffusion bonded to a machined Inconel injector body. The injector body had provisions for direct mounting of the flanged main injector valves that supplied the primary propellant circuits, for the igniter assembly discussed above, and for instrumentation ports. The instrumentation ports enabled measurements of manifold pressures and temperatures, main engine chamber pressure, injector face temperatures, and acoustic cavity gas temperatures. High frequency transducers $\left(\right.$ Kistler $^{\circledR}$ ) were mounted in the vernier fuel and the primary fuel manifolds for detection of high frequency acoustic instabilities in the combustion chamber. Other manifold pressures and the main chamber pressure

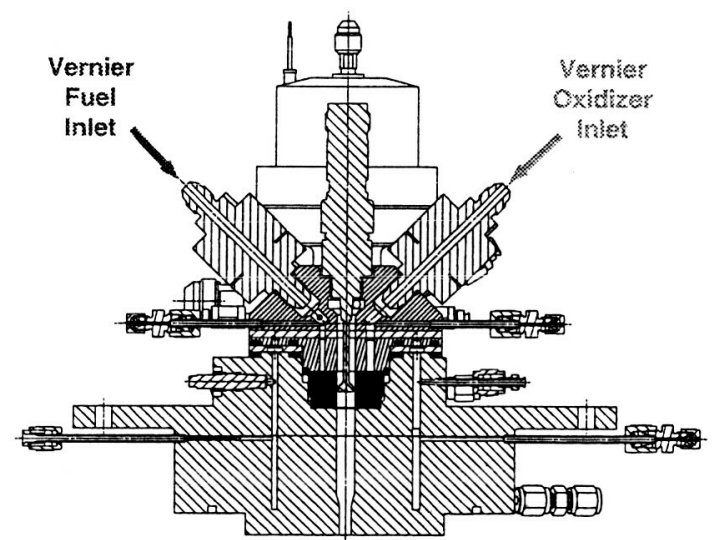

Figure 3. Cross Section of the Igniter and Injector Interface were measured using standard Tabor ${ }^{\circledR}$ pressure transducers.

\section{Combustion Chamber}

The combustion chamber was machined from a forged billet of C-103 columbium, and was di-silicide coated with R512E to provide oxidation protection. The 15-degree half-angle conical nozzle was truncated at an expansion area ratio, $\varepsilon$, of $3: 1$ to accommodate ambient testing and to facilitate extrapolation of performance (Isp) to higher area ratios. As previously discussed, the engine design flow rates were determined for a thrust of $870 \mathrm{lbf}$, which was consistent with an expansion area ratio of 22:1; hence, the vacuum corrected thrust for the truncated 3:1 nozzle was lower, being $762 \mathrm{lbf}$. 


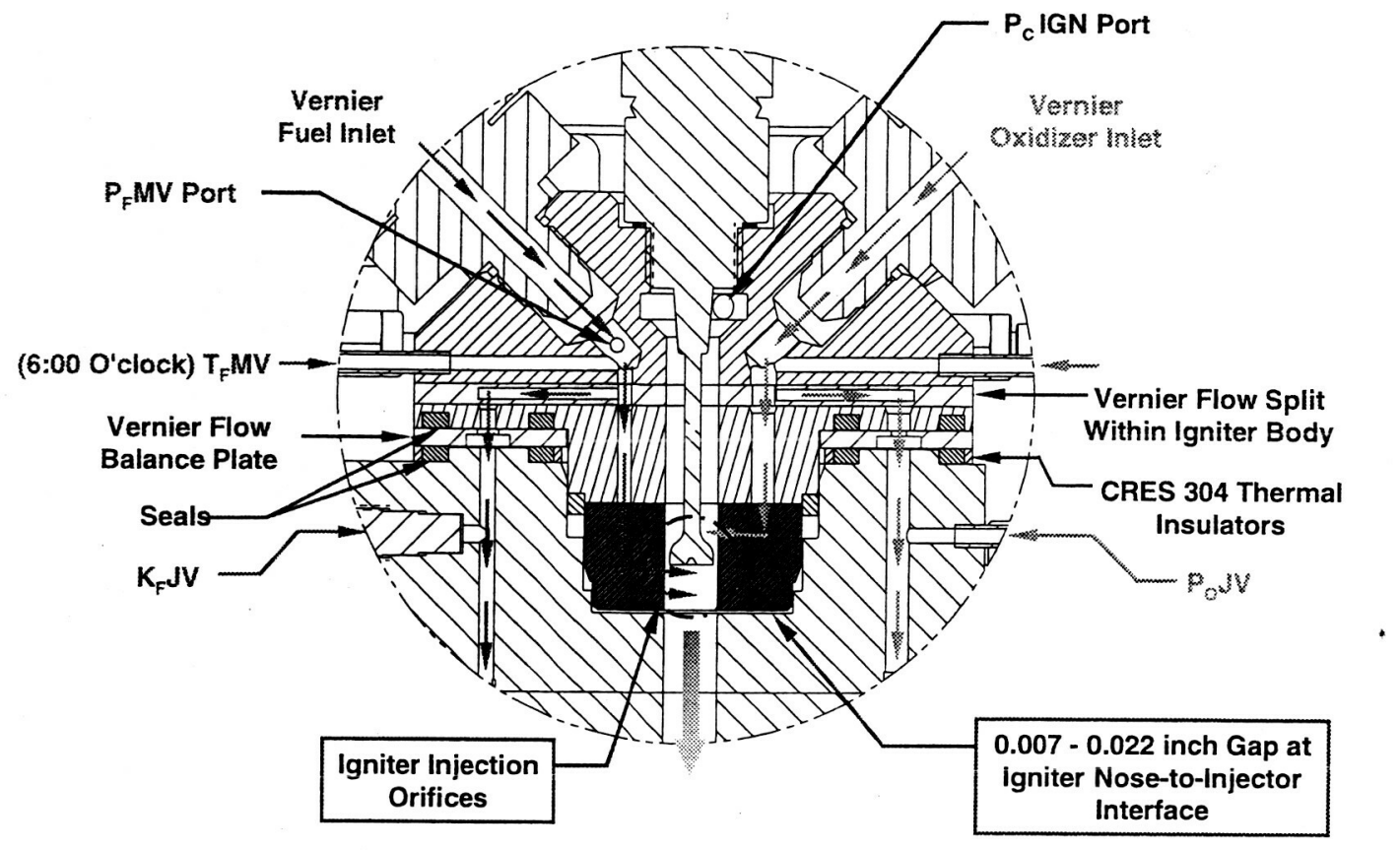

Figure 4. Vernier Propellant Circuit Flow Diagram

\section{Valves}

The engine was designed with two sets of valves: one set for the igniter/vernier oxidizer and fuel, and one set for the injector/primary oxidizer and fuel. Each valve set was a direct-acting solenoid type, designed to open and close rapidly to enable an electrical pulse width (EPW) of 0.080 seconds to be completed by the engine. The igniter (vernier) valves were designed and developed in association with Castor Engineering, and the injector (primary) valves with Moog.

5. Exciter

To initiate the ignition process within the igniter assembly, electrical signals of sufficient voltage, energy level, and frequency must be supplied to the igniter spark plug. Unison Industries designed and developed the exciter used on the dual thrust RCE.

\section{Test Objectives}

The test objectives for the dual thrust RCE were to evaluate steady state and pulsing characteristics for each of the two operating modes: vernier $(25 \mathrm{lbf})$ and primary (870 lbf). To establish representative pulsing duty cycles, the planned NASA WSTF APS System Level test matrix was evaluated, and combined with the contract requirements, seven different electrical pulse widths (EPW) and four different percent duty cycles were defined. The resulting pulse trains, summarized in Table 2 , were to be performed for vernier and primary operating modes. Pulse trains A, B and C came directly from the contract
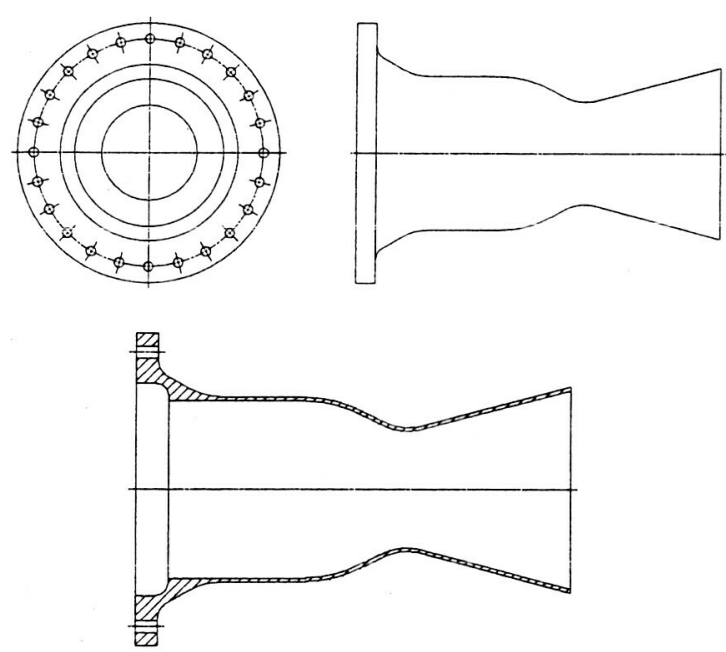

Figure 5. Combustion Chamber Truncated at an Expansion Ratio of 3:1 Statement of Work, whereas pulse trains $D$ and $E$ were recommended by an Aerojet independent review team to bridge the gap between the very short 0.080 second EPW, and the next longest EPW of 1.0 second. Finally, pulse trains $F$ and $G$ were determined to be the most thermally aggressive tests planned for the WSTF system level testing based on analysis of chamber heating and post-test thermal soakback characteristics. 


\section{A. Vernier Test Objectives}

The vernier test series was the first opportunity to evaluate the newly developed LOX/Ethanol igniter integrated with the injector vernier circuit. Consequently, one of the test objectives was to determine the LOX/Ethanol ignition characteristics for the igniter and the main chamber over the planned range of vernier mode operation.

Additional test objectives focused on steady state operating conditions, which included nominal and off-nominal steady state tests to assess the effect of varying Pc and MR. Other steady state objectives included determination of engine performance (Isp), combustion stability monitoring, and thermal characteristics of the injector and chamber.

Objectives for the pulse testing included evaluation of the engine response for the different pulse trains at nominal operating conditions, i.e., Pc of 4.8 psia and MR of 1.35 . Specifically, pulse mode response and pulseto-pulse repeatability were a concern due to the relatively low LOX flow rates during vernier operation when contrasted with the size of the hardware. In addition, injector and chamber thermal characteristics were to be determined during pulse testing.

\section{B. Primary Test Objectives}

The primary test objectives paralleled the vernier objectives, in that engine operating characteristics were to be evaluated for steady state and pulse mode operation. The steady state tests were to determine the effects on engine operation of varying Pc and MR, including determination of the performance (Isp), the injector thermal characteristics and the chamber temperature profiles. High frequency combustion stability and low frequency combustion stability (chug) were also to be monitored during steady state tests.

Pulse mode operation at nominal conditions, i.e., Pc of 150 and MR of 1.5, was to establish engine pulse mode response and pulse-to-pulse repeatability. Injector thermal characteristics (face and body temperatures), as well as chamber temperature profiles were to be monitored during pulse testing.

\section{Test Setup}

The vastly different chamber pressures for the vernier and primary operating modes required two different test setups. The very low vernier chamber pressure of 5.0 psia required an altitude test cell to ensure full flow through the nozzle, whereas, the primary chamber pressure of 150 psia permitted testing at ambient pressure. Consequently, the testing was split between two test cells in the A-Zone Research and Development Laboratories at the Aerojet Sacramento facility. The vernier testing was conducted in Test Cell A-2, an altitude test cell, and the primary testing was conducted in Test Cell A-5, an ambient test cell. The altitude facility of Test Cell A-2 provided an equivalent altitude of approximately 175,000 feet at the start of a test, and a sustained equivalent altitude of approximately 90,000 feet for steady state operation at $25 \mathrm{lbf}$ thrust.

Although the two test cells required entirely different setups, a modular thrust structure was developed that enabled the engine, as well as the pressure instrumentation and purge valves, to be assembled in a clean room and then transported to the appropriate test cell and installed on the thrust stand. This modular arrangement also provided for close coupling of the purge valves and pressure transducers to minimize the dribble volume on each

6 
propellant circuit, thus improving manifold fill times and transducer response time. The modular thrust structure is depicted in Fig. 6 with the engine installed.

\section{A. Vernier Test Setup}

The vernier test setup plumbed propellant lines to the oxidizer and fuel igniter valves, which fed the igniter and the injector vernier circuits. The main injector (primary) valves were installed, but not connected to propellant lines; however, gaseous nitrogen $\left(\mathrm{GN}_{2}\right)$ purge lines were attached to the manifolds of the injector primary propellant circuits to provide purging capability through the injector primary oxidizer and fuel passages between vernier tests.

The modular thrust structure was mounted in the test cabin of the Test Cell A-2 altitude facility after the engine, purge valves and pressure transducers were mounted and leak checked. The installed configuration is depicted in Fig. 7, where the pressure transducers and purge valves are visible in the top left of Fig. 7a. A heat shield, visible on the left side of Fig. $7 b$, was installed to protect the instrumentation and electrical cabling from thermal radiation during long duration tests. Vernier testing during the Basic phase revealed thermal effects on the thrust measurement load cells, as well as the propensity to melt the insulation on the electrical cabling during long duration firings. A water-cooled diffuser, visible on the right side of Fig. 7b, was installed between the test cabin and the 11,000 cubic foot altitude chamber to assist in maintaining an acceptable back-pressure to ensure a full flowing nozzle.

Extensive instrumentation was installed on the vernier engine configuration. This instrumentation measured valve inlet and manifold pressures and temperatures on each of the propellant circuits, and temperatures within the injector body. The injector body temperatures were of interest to evaluate thermal soakback after a firing. In addition, the combustion chamber was instrumented with 24 chromel-alumel (C/A Type K) thermocouples, arranged as indicated in Fig. 8, to monitor chamber longitudinal and circumferential temperature profiles. The circumferential positions were based on the features of the primary and vernier injector patterns. Thrust and propellant flow rates were measured during steady state tests for determining Isp, but prior to commencing pulse testing, the flow meters were removed to prevent them from being damaged.

\section{B. Primary Test Setup}

For primary testing, the injector vernier passages were blocked off so that the propellant entering the igniter valves flowed through the igniter only. The same modular thrust structure was employed, and after assembling the engine, instrumentation and purge valves to the structure, leak check tests were performed prior to installation into Test Cell A-5 (Fig. 9).

Propellant was plumbed to the igniter valves and the main injector valves, with the igniter propellant lines branching off the main propellant feed lines. Flow meters were used to measure the total LOX and ethanol flow rates, as well as the individual igniter LOX and ethanol flow rates. The difference between the two sets of measured flow rates

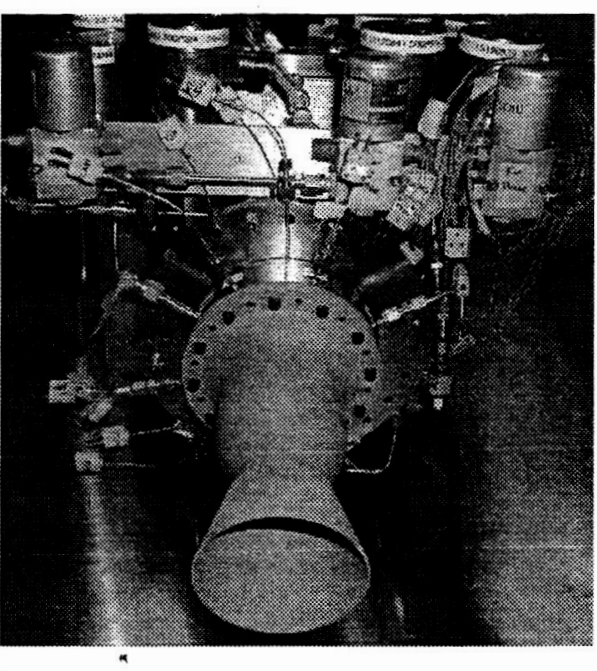

Figure 6. Engine Installed on Modular Thrust Structure

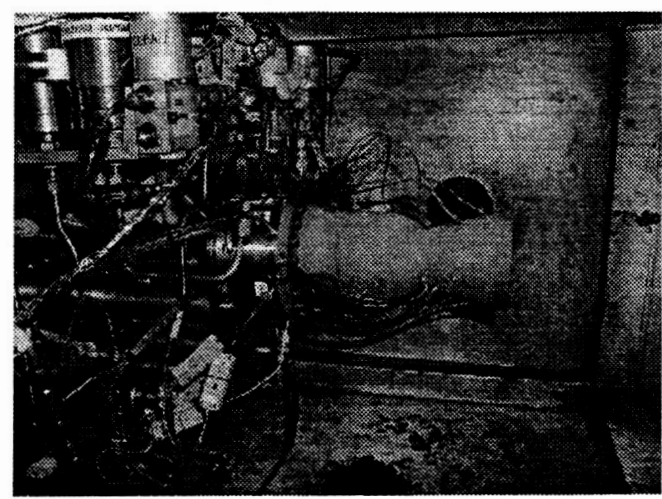

a)

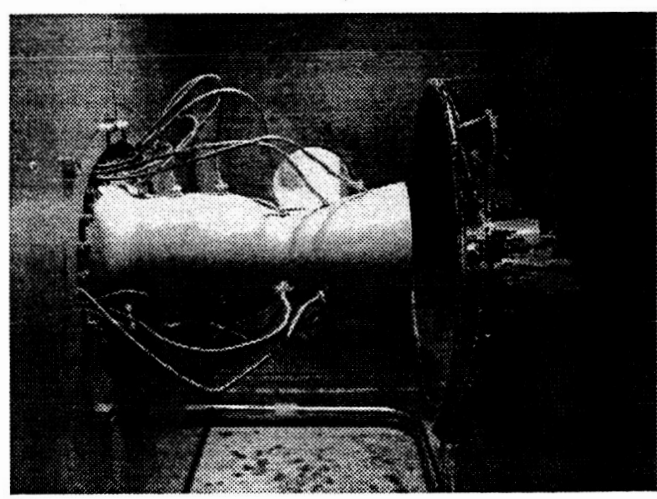

b)

Figure 7. Vernier Engine Configuration Installed in the Test Cabin of the A-2 Altitude Test Cell 
determined the injector LOX and ethanol flow rates. The flow rates and the test stand thrust load cells were used to determine Isp for primary steady state operation. And similar to vernier testing, the flow meters were removed prior to initiating pulse testing to prevent them from being damaged.

Like the vernier configuration, extensive pressure and temperature instrumentation was installed to monitor the engine during primary testing. This instrumentation measured valve inlet and manifold pressures and temperatures on each of the propellant circuits, and temperatures within the injector body. Injector face thermocouples were also successfully installed. Chamber temperature instrumentation for primary testing was identical to the vernier configuration (Fig. 8).

\section{Vernier Test Results}

\section{A. Summary}

The vernier test series explored steady state and pulse mode operation of the engine in two operating configurations: full vernier configuration and igniter-only vernier configuration. The full vernier configuration was as described above and shown in Fig.4. Igniter-only vernier configuration was achieved by removing the vernier flow balance plate and blanking off the oxidizer and fuel vernier flow passages at the interface between the igniter and the injector. The igniter-only vernier configuration was selected after encountering difficulties during pulse testing in the full vernier configuration because of the effect varying LOX quality had on pulsing characteristics.

A total of 109 hot fire tests were performed in vernier mode, with 56 of them performed in the full vernier configuration and 53 in the igniter-only vernier configuration. Of the 56 tests performed in full vernier configuration, 51 of them were steady state tests and 5 were pulse tests. Most of the 51 steady state tests were spent evaluating the effects of varying LOX quality on manifold fill times and main chamber ignition lags. The main chamber ignition timing was highly dependent on igniter LOX valve inlet pressures and temperatures. Of the 51 steady state tests, nine of them were long duration: one for 120 seconds, four for 240 seconds, and four for 360 seconds. In addition to the main chamber ignition lags, the thrust profiles of the limited number of pulse tests showed less than desirable pulse response and pulseto-pulse repeatability due to the low vernier flow rates. The primary-to-vernier thrust ratio of 34.8 was too large for a dual thrust design, as the primary thrust level determines the physical size of the engine, but the vernier mode must still operate successfully within that defined size.

As a result of the less than desirable pulse performance in full vernier configuration, the decision was made to switch to igniter-only vernier configuration. During igniter-only operation, the chamber pressure and mixture ratio

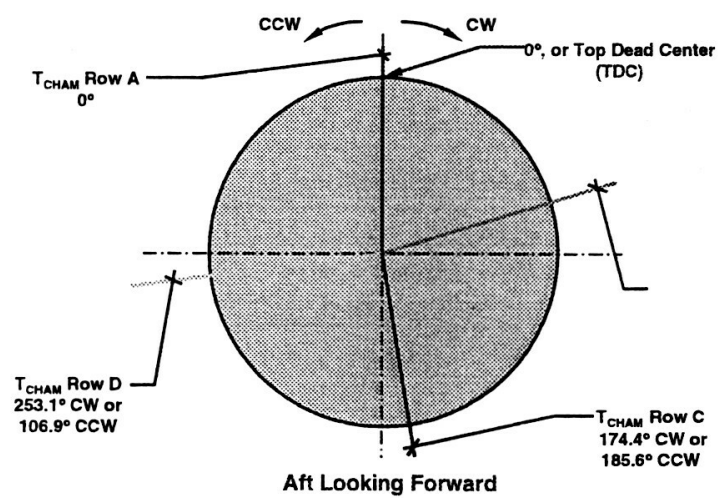

a) Circumferential Orientation of TCHAM

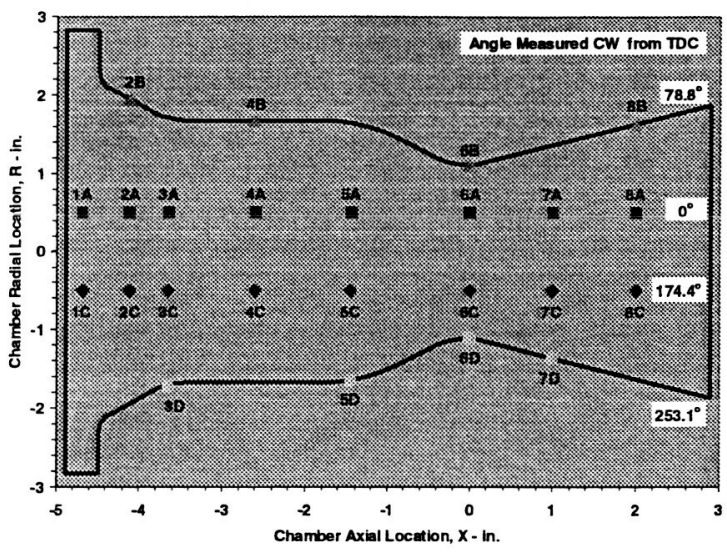

b) Axial Orientation of TCHAM

Figure 8. Orientation of Chamber Mounted Thermocouples (TCHAM)

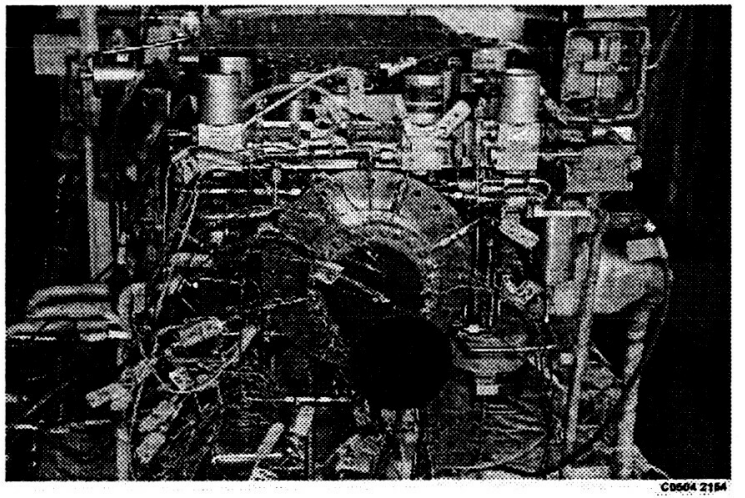

Figure 9. Primary Engine Configuration Installed on the Test Stand in Test Cell A-5 
were increased over the nominal design point to obtain higher thrust. Of the 53 tests run in igniter-only mode, 29 were steady state tests and 24 were pulse tests. None of the steady state tests performed in the igniter-only configuration exceeded 20 seconds duration, since there was no FFC as a result of blanking off the oxidizer and fuel vernier flow passages at the interface between the igniter and the injector.

The two configurations evaluated during vernier testing (full vernier and igniter-only vernier) accumulated a combined total of 6,670 seconds of firing time, and 7,215 pulses. The types of tests, quantity, test duration and numbers of pulses are summarized in Table 3 by test configuration, and the pulse count for each electrical pulse width (EPW), or pulse designation, is summarized in Table 4. The difference in the pulse totals between Tables 3 and 4 is accounted for by the contribution of the steady state tests. It should be noted that Pulse Train G was not tested, as its 15.040 second EPW was considered to be like a series of steady state tests strung together. In addition, there were no combustion instabilities encountered during the primary testing as determined by a combustion stability monitor (CSM) coupled with a high frequency Kistler ${ }^{\circledR}$ transducer installed in the injector fuel manifold.

Table 3. Summary of Vernier Testing

\begin{tabular}{|c|c|c|c|c|}
\hline $\begin{array}{c}\text { Test } \\
\text { Configuration }\end{array}$ & Test Type & $\begin{array}{c}\text { No. of } \\
\text { Tests }\end{array}$ & $\begin{array}{c}\text { Test } \\
\text { Duration, s }\end{array}$ & $\begin{array}{c}\text { No. of } \\
\text { Pulses }\end{array}$ \\
\hline \hline Full Vernier & Steady State & 51 & $3,419.2$ & 58 \\
\hline & Pulsing & 5 & 121.7 & 299 \\
\hline \hline & Subtotal: & 56 & $3,540.9$ & 357 \\
\hline \hline Igniter Only & Steady State & 29 & 266.8 & 26 \\
\hline & Pulsing & 24 & $2,862.3$ & 6,832 \\
\hline \hline & Subtotal: & 53 & $3,129.1$ & 6,858 \\
\hline \hline \multicolumn{2}{r|}{ Vernier Testing Total: } & $\mathbf{1 0 9}$ & $\mathbf{6 , 6 7 0}$ & $\mathbf{7 , 2 1 5}$ \\
\hline
\end{tabular}

Table 4. Vernier Pulse Count Totals by Electrical Pulse Width

\begin{tabular}{|c|c|c|}
\hline Pulse & EPW, $s$ & Count \\
\hline A & 0.080 & 2,476 \\
\hline B & 1.000 & 760 \\
\hline $\mathrm{C}$ & 10.0 & 17 \\
\hline $\mathrm{D}$ & 0.160 & 1,333 \\
\hline$E$ & 0.320 & 2,170 \\
\hline $\mathrm{F}$ & 2.560 & 375 \\
\hline & Total: & 7,131 \\
\hline
\end{tabular}

\section{B. Full Vernier Configuration}

\section{Steady State Tests}

Steady state tests evaluated the effects of varying Pc and MR on engine performance and on thermal response. Pc was varied from 3.57 to 5.96 psia and MR was varied from 1.20 to 1.72. Vacuum corrected thrust (Fvac) and vacuum Isp showed corresponding variations for the ranges of Pc and MR tested, with Fvac and vacuum Isp values ranging from 20.2 to $34.0 \mathrm{lbf}$ and 154 to $217 \mathrm{lbf}-\mathrm{sec} / \mathrm{lbm}$, respectively, for the $\varepsilon$ of 3:1 that was tested. A summary plot of Pc and MR combinations is shown in blue in Fig. 10 for the full vernier configuration tests, and the corresponding Isp versus MR is similarly shown in blue in Fig. 11.

The Isp obtained in the full vernier configuration was less than expected on average, and somewhat variable, as evidenced by the spread in Fig. 11. When compared with the Isp obtained during the Basic phase vernier tests, ${ }^{3}$ the

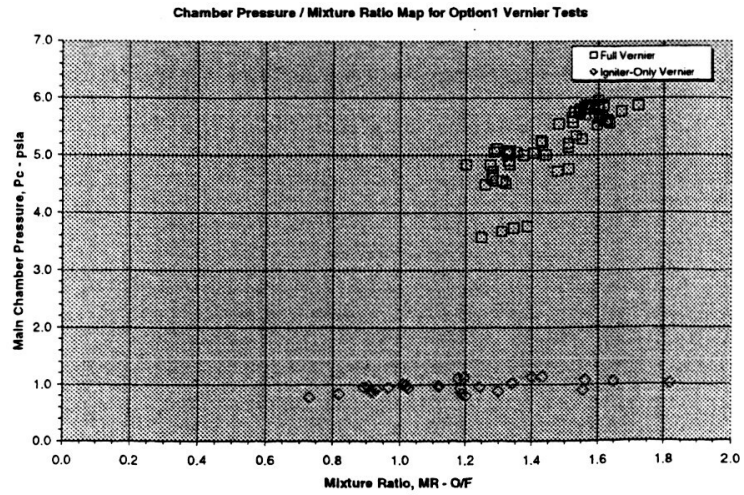

Figure 10. MR and Pc Ranges Tested in Vernier Mode

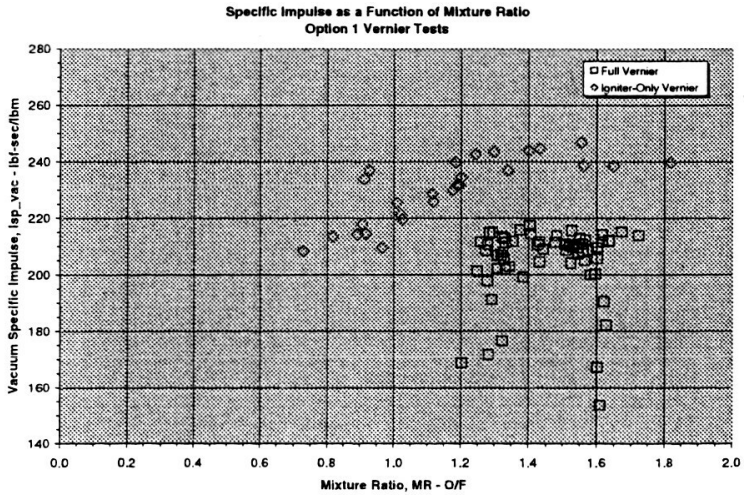

Figure 11. Range of Isp Obtained for Vernier Tests at $\varepsilon=3$

9 


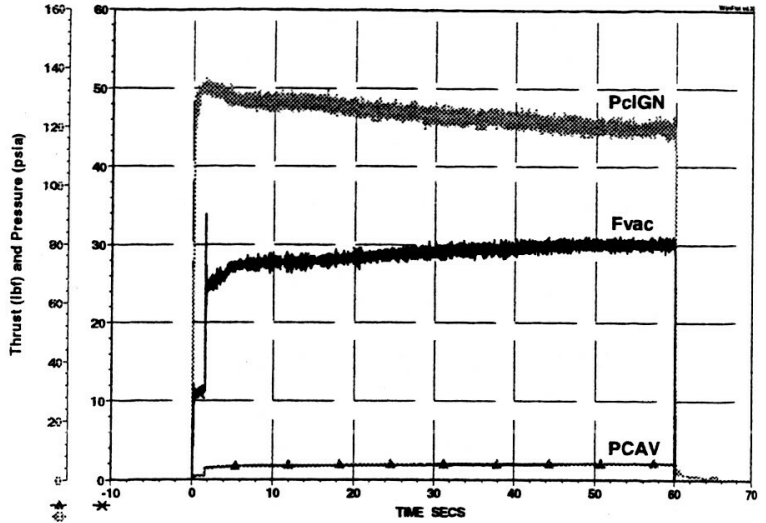

Figure 12. Full Vernier Test 139 - Thrust and Chamber Pressure

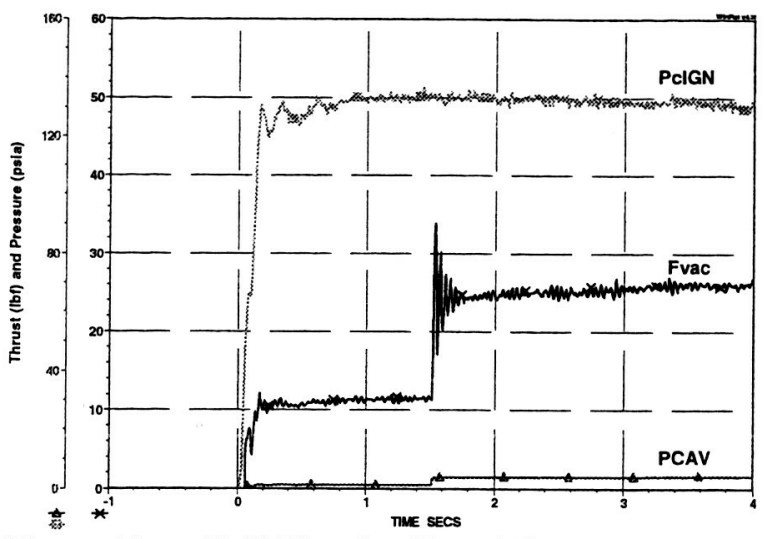

Figure 13. Full Vernier Test 139 - Thrust and Chamber Pressure - Start Transient

Option 1 full vernier Isp was running approximately 12-30 lbf-sec/lbm lower. However, the chamber $\mathrm{L}^{\prime}$ in the Basic phase vernier testing was longer (5.75 in.) than for Option 1 (4.50 in.), and the number of elements in the Basic phase vernier injector was greater, which would help support the observed differences in Isp.

Significant variations in the timing of the main chamber ignition were also observed during testing. A representative plot of Fvac, PCAV, and PcIGN depicted in Fig. 12 was taken from Vernier Test 139. PcIGN shows immediate ignition, but the chamber pressure, PCAV, shows a delay in main chamber ignition. When the main chamber ignites, there is a corresponding jump in Fvac. An enlarged view of the start of Test 139 is presented in Fig. 13, where the main chamber ignition delay is more apparent than in Fig. 12. An even more significant comparison is seen in Fig. 14, where the main chamber pressure, PCAV, is plotted from three different tests (126, 127 and 134). The ignition delays were $0.120,2.314$, and 11.842 seconds for Tests 134,126 , and 127, respectively. This variable ignition delay was one of the motivations for testing an igniter-only configuration.

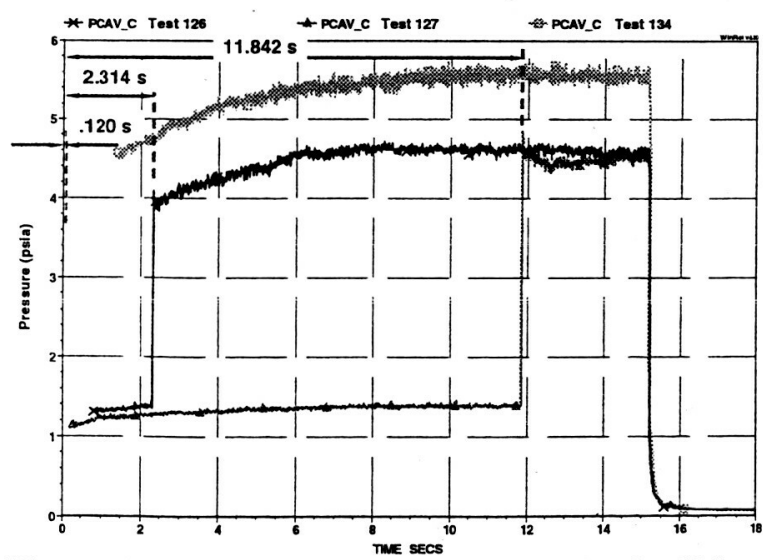

Figure 14. Vernier Tests 126, 127, \& 134 Chamber Pc Comparison - Main Chamber Ignition Delay

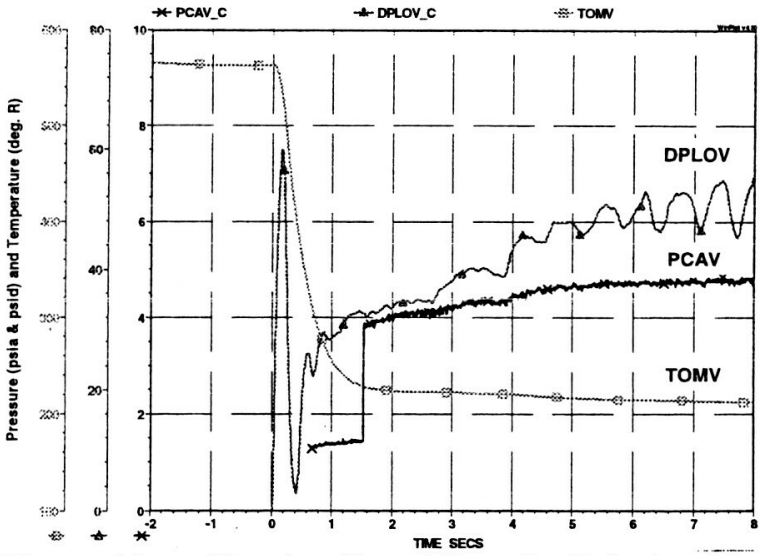

Figure 15. Vernier Test 139 - Pc Relationship to Manifold Temperature

Part of the explanation for the variable ignition delay was the varying quality of LOX from test to test. The variability in LOX quality was directly related to the igniter valve inlet pressure, i.e., the higher the pressure, the shorter the ignition delay. A good indicator of LOX quality was the LOX vernier manifold temperature, TOMV. As seen in Fig. 15, vernier LOX flow, as determined by the differential pressure DPLOV, did not become established until the manifold temperature (TOMV) dropped significantly, i.e., passed through the saturation line, which took around 1.0-1.5 seconds. At the point the saturation line was crossed, LOX flow increased and the main chamber ignited, as evidenced by the jump in PCAV. In retrospect, the low flow rates of the vernier (25 lbf) 

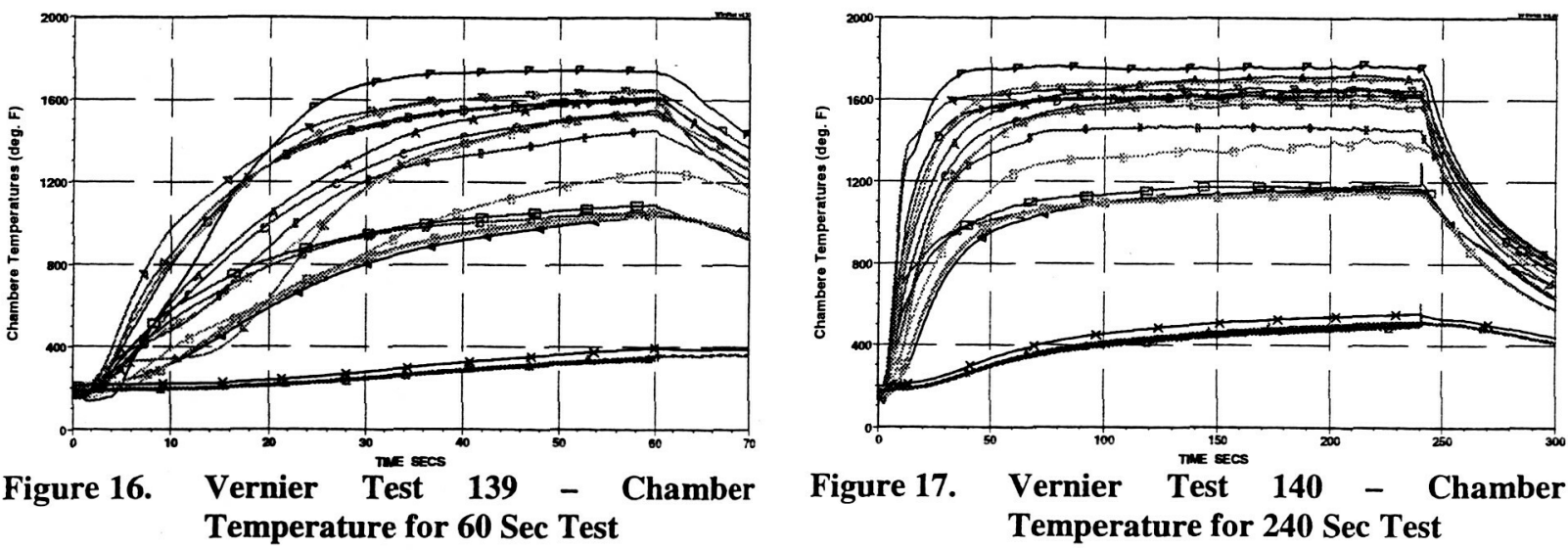

Figure 17. Vernier Test 140 - Chamber Temperature for $240 \mathrm{Sec}$ Test

operating level cannot adequately chill in the relatively large hardware over a short time period, as it was sized for the 870 -lbf operating point. A larger vernier thrust level is required to go with the $870 \mathrm{lbf}$ primary mode, or to put it another way, a thrust ratio of 34.8 of primary to vernier is just too large to get adequate cryogenic flow rates in a reasonable time frame.

From a thermal point of view, the engine performed well in the full vernier mode, probably aided by the low vernier chamber pressures. Chamber temperature (TCHAM) profiles for Test 139 (60 second test) are plotted in Fig. 16, where chamber temperatures have for the most part leveled off at the end of 60 seconds. The highest chamber temperatures recorded in Fig. 16 are TCHAM 5B and 3B, having values of $1,742{ }^{\circ} \mathrm{F}$ and $1,647{ }^{\circ} \mathrm{F}$, respectively, which are low values for coated columbium chambers. During Test 139 , the injector face temperature (TINJF) reached $202^{\circ} \mathrm{F}$, which is also cool for an injector face. For comparison, TCHAM for Test 140, a long (240 second) duration test, is presented in Fig. 17, where the chamber temperatures are not much warmer than for the 60 second test of Fig. 16. The highest chamber temperatures for Test 140 are again captured by TCHAM 5B and 3B with values of $1,766^{\circ} \mathrm{F}$ and $1,704^{\circ} \mathrm{F}$, respectively. The corresponding injector face temperature (TINJF) for Test 140 was $287^{\circ} \mathrm{F}$.

\section{Pulse Tests}

Only a few pulse tests were completed on the full vernier configuration before the decision was made to change to the igniter-only configuration. The pulse train tested during Test 152 was a $0.320 \mathrm{EPW}$ at $50 \% \mathrm{DC}$ (E-50\%), and the poor response and lack of pulse-to-pulse repeatability are graphically displayed in Fig. 18 and 19, where representative pulses are shown at the beginning and near the end of the test, respectively. In contrast, the same pulse train was run during Test 199 , which was performed with the igniter-only configuration, and the thrust profiles are crisp and very repeatable, also as evidenced by the plot of Fig. 19.

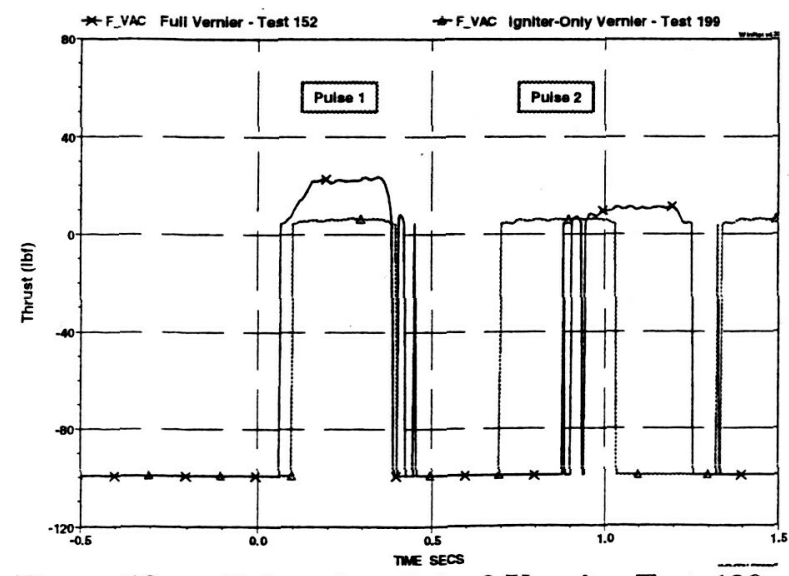

Figure 18. Pulses 1 and 2 of Vernier Test $\overline{139}$. Thrust

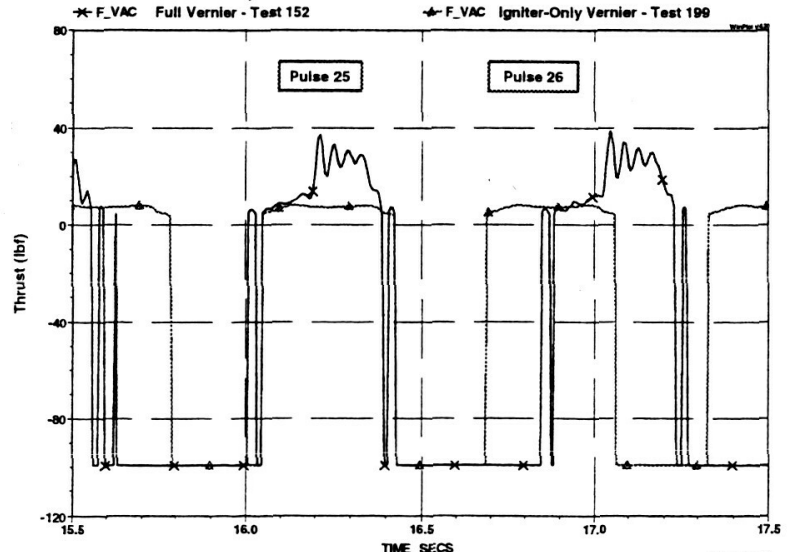

Figure 19. Pulses 25 and 26 of Vernier Test 139 Thrust

11

American Institute of Aeronautics and Astronautics 


\section{Igniter-Only Vernier Configuration}

\section{Steady State Tests}

Steady state tests evaluated the effects of varying Pc and MR on engine thrust and performance. Since there was no FFC during tests run for the igniter-only configuration, the test duration was generally limited to nothing greater than 15 seconds, as the engine was essentially operated as a heat sink. Pc was varied from 0.78 to 1.14 psia and MR was varied from 0.73 to 1.82 . Vacuum corrected thrust (Fvac) and vacuum Isp showed corresponding variations for the ranges of Pc and MR tested, with Fvac and vacuum Isp values ranging from 8.0 to $12.1 \mathrm{lbf}$ and 208 to $247 \mathrm{lbf}-$ sec/lbm, respectively. A summary plot of Pc and MR combinations is shown in red in Fig. 10 for the igniter-only vernier configuration tests, and the corresponding Isp versus MR is similarly shown in red in Fig. 11.

The Isp obtained in the igniter-only vernier configuration was greater than expected on average, and reasonably consistent, as evidenced by the spread in Fig. 11. When compared with the Isp obtained during the Basic phase vernier tests, the Option 1 igniter-only vernier Isp was running approximately 5-15 lbf-sec/lbm higher. No FFC coupled with better mixing within the igniter helped support the observed gains in Isp.

As might be expected, ignition timing was not an issue, and high chamber temperatures were an issue. With no FFC, chamber temperatures continued to rise throughout a given test; hence, the imposed limit of 15 seconds on test duration for igniter-only operation.

Pulse Tests

In contrast with the full vernier configuration tests, many pulsing tests were performed in igniter-only mode. The only issue during pulse testing was chamber temperature, as long pulse trains had a tendency to overheat the chamber. As previously mentioned, the E-50\% pulse train that was run during Test 152 for full vernier configuration, was repeated on Test 199 for igniter-only configuration. The thrust profiles from each test were plotted together in Fig. 18 and 19, where pulses at the beginning and near the end of the Test 152 are compared. The thrust profiles were crisp and very repeatable for the igniter-only mode.

\section{Primary Test Results}

\section{A. Summary}

The primary test series explored steady state and pulse mode operation of the engine at the 870-lbf thrust level $(\varepsilon=22: 1)$. Recall that the $870-\mathrm{lbf}$ term is used in reference to the vacuum developed thrust the engine would provide with a nozzle having an expansion ratio, $\varepsilon$, of $22: 1$. As the RCE test article had a 15-degree conical nozzle truncated to 3:1 (to facilitate ambient testing), the actual vacuum corrected thrust at nominal Pc and MR was $762 \mathrm{lbf}$. A total of 71 hot fire tests were performed in primary mode, with 34 of them being steady state tests and 37 of them pulsing tests. The 34 steady state tests evaluated engine performance for nominal $\mathrm{Pc}$ and $\mathrm{MR}$, for varying $\mathrm{Pc}$ and $\mathrm{MR}$, and of an insulated chamber at nominal Pc and MR. The 37 pulse tests determined engine response to the pulsing duty cycles defined in Table 2 .

The primary testing accumulated a combined total of 2,060 seconds of firing time, and 3,646 pulses. The types of tests, quantity, test duration and numbers of pulses are summarized in Table 5, and the pulse count for each electrical pulse width (EPW), or pulse designation, is summarized in Table 6. The difference in the pulse totals between Tables 5 and 6 is accounted for by the contribution of the steady state tests. It should be noted that Pulse Train G was not tested, as its 15.040 second EPW was considered to be like a series of steady state tests strung together. So in the interest of focussing available test time on the other EPW's, pulse train G was dropped from the

Table 5. Summary of Primary Testing

\begin{tabular}{|c|c|c|c|}
\hline Test Type & $\begin{array}{c}\text { No. of } \\
\text { Tests }\end{array}$ & $\begin{array}{c}\text { Test } \\
\text { Duration, } \mathbf{s}\end{array}$ & $\begin{array}{c}\text { No. of } \\
\text { Pulses }\end{array}$ \\
\hline \hline Steady State, Uninsulated & 33 & $1,255.7$ & 48 \\
\hline Steady State, Insulated & 1 & 30.2 & 1 \\
\hline \hline Pulsing & 37 & 774.4 & 3,597 \\
\hline Primary Testing Total: & $\mathbf{7 1}$ & $\mathbf{2 , 0 6 0}$ & $\mathbf{3 , 6 4 6}$ \\
\hline
\end{tabular}

Table 6. Primary Pulse Count Totals by Electrical Pulse Width

\begin{tabular}{|c|c|c|}
\hline Pulse & EPW, s & Count \\
\hline $\bar{A}$ & 0.080 & 2,543 \\
\hline B & 1.000 & 65 \\
\hline $\mathrm{C}$ & 10.0 & 10 \\
\hline $\mathrm{D}$ & 0.160 & 460 \\
\hline$E$ & 0.320 & 444 \\
\hline $\bar{F}$ & 2.560 & 75 \\
\hline & Total: & 3,597 \\
\hline
\end{tabular}


test matrix. In addition, there were no combustion instabilities encountered during the primary testing as determined by a combustion stability monitor (CSM) coupled with a high frequency $\operatorname{Kistler}^{\circledR}$ transducer installed in the injector fuel manifold.

\section{B. Steady State Tests}

The steady state tests established a baseline nominal engine operation at a Pc and MR of 150 psia and 1.5, respectively, and then evaluated the effects on engine performance and thermal response of varying Pc and MR about the nominal point. During the test series, Pc was varied from 103 to 179 psia and MR was varied from 1.33 to 1.76. Vacuum corrected thrust (Fvac) and vacuum corrected Isp (Isp,vac) reflected corresponding variations for the different Pc and MR combinations tested. Fvac ranged from 535 to $911 \mathrm{lbf}$, reflecting a range of approximately70\% to $120 \%$ of nominal thrust. The corresponding Isp,vac values for the same range were 249.3 to $247.9 \mathrm{lbf}$-sec/lbm for the nozzle area ratio of 3 that was tested. A summary plot of the Pc and MR combinations tested are given in Fig. 20, and a summary plot of Isp,vac as a function of MR is shown in Fig. 21. Note that all of the Pc / MR survey tests were 60 seconds in duration for direct comparison of like test parameters, and to ensure that the combustion chamber temperatures reached steady state values.

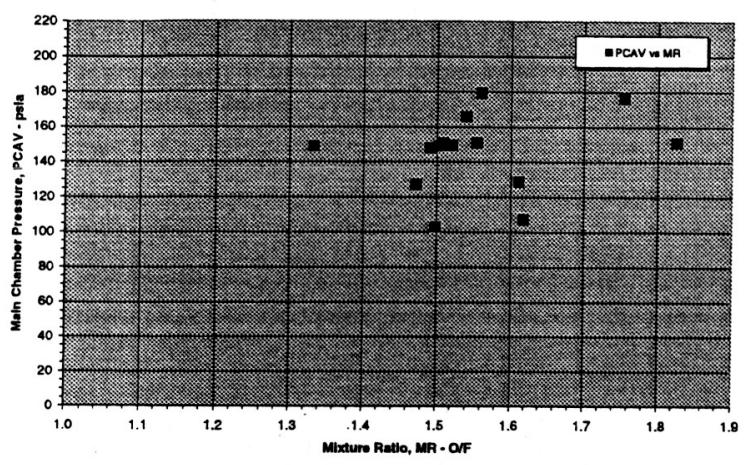

Figure 20. MR and Pc Ranges Tested in Primary Mode

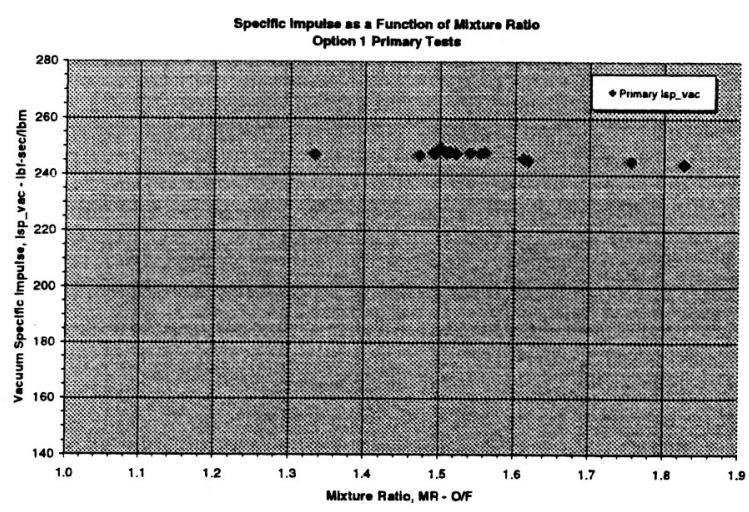

Figure 21. Range of Isp Obtained for Primary Tests for $\varepsilon=3$

The Isp,vac obtained during the Option 1 primary testing compared favorably with the results from the Basic phase primary testing. The nominal Option $1 \mathrm{Isp}, \mathrm{vac}$ was $247.4 \mathrm{lbf}-\mathrm{sec} / \mathrm{lbm}$, compared with the Basic phase nominal value of $245.7 \mathrm{lbf}-\mathrm{sec} / \mathrm{lbm}$. Increased injector element quantity most likely accounted for the $1.7 \mathrm{lbf}$ $\mathrm{sec} / \mathrm{lbm}$ increase in Isp,vac. Performance for an insulated 22:1 nozzle was established through analysis, by accurate analytical determination ${ }^{8}$ of the kinetics, divergence and boundary layer losses associated with the higher area ratio nozzle. The Isp,vac at the 22:1 nozzle area ratio, for a nominal Pc of 150 psia and MR of 1.5 , was $287.6 \mathrm{lbf}$ $\mathrm{sec} / \mathrm{lbm}$, with a corresponding delivered thrust of $884.3 \mathrm{lbf}$, exceeding the goal of $870 \mathrm{lbf}$.

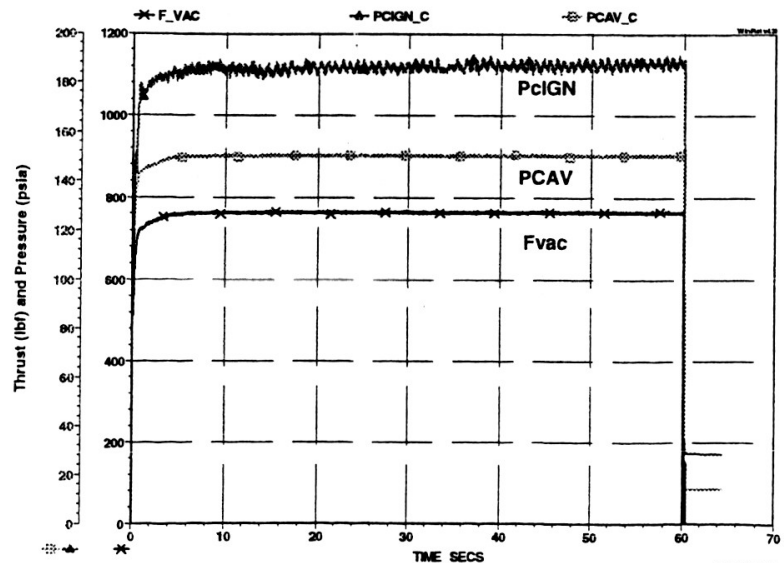

Figure 22. Thrust and Chamber Pressure for 60Sec Primary Test (Test 112)

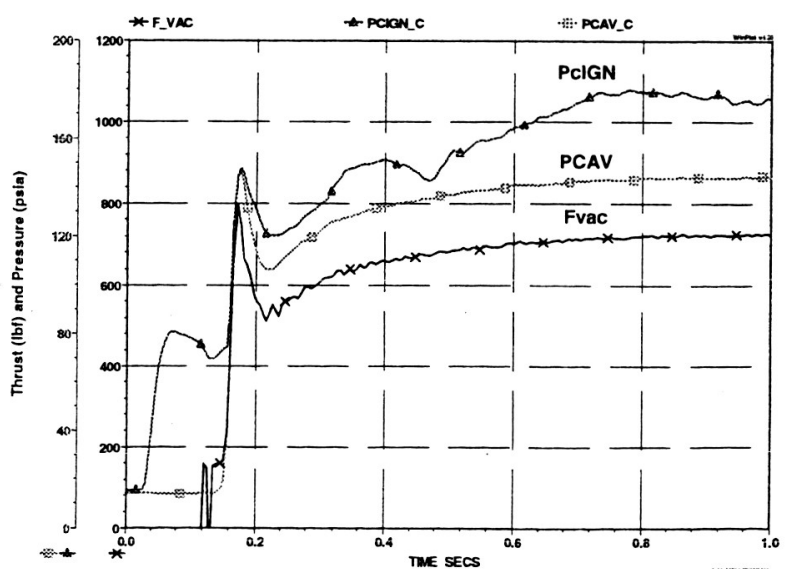

Figure 23. Thrust and Chamber Pressure During Ignition Start Transient for 60-Sec Primary Test (Test 112)

13 
A typical plot of Fvac, PCAV and PcIGN for the 60-second steady state nominal baseline test (Test 112) is depicted in Fig. 22, with the start of ignition shown in Fig. 23. Main chamber ignition (PCAV) delay is minimal at 140 milliseconds behind PcIGN, when compared with the 1-1.5 seconds observed in Fig. 13 for the full vernier configuration. There were no ignition delay issues observed during primary testing. In addition, the chill-in of the injector LOX manifold was rapid, as evidenced by the steep decline of the injector LOX manifold temperature (TOJ) in Fig. 24. The LOX saturation temperature shown in Fig 24 was calculated from the measured manifold pressures, and added to the plot as a means of making a qualified assessment of when the LOX manifolds transition from two-phase flow to liquid flow. Vernier and primary chill-in of the LOX circuits were compared in Fig. 25, where PCAV and TOMV from Fig. 15 were plotted with PCAV and TOJ from Fig. 25.

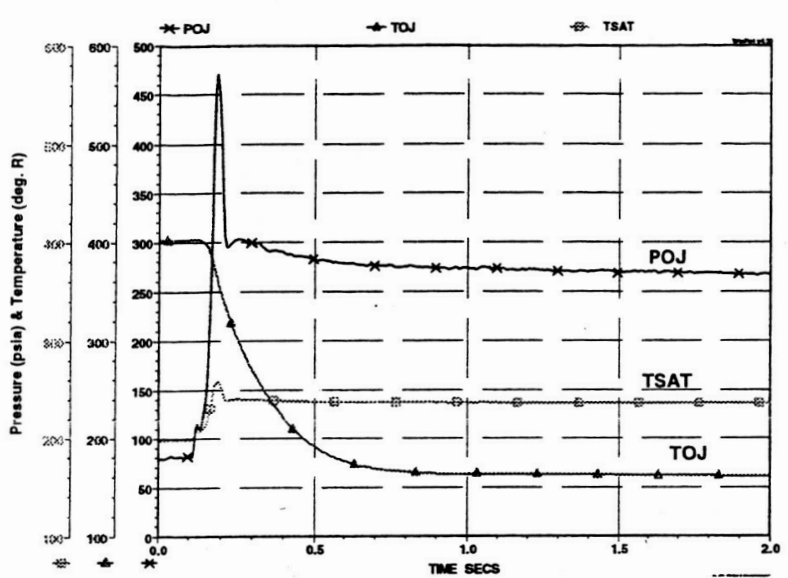

Figure 24. Primary Test - Oxidizer Manifold Temperature and Pressure

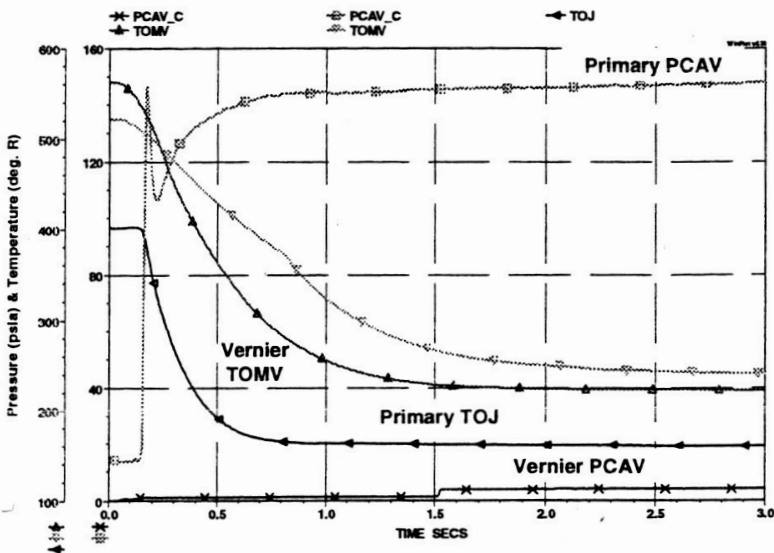

Figure 25. Comparison of Primary and Vernier Test Oxidizer Circuit Chill-in

Chamber temperature profiles were obtained for each primary test, and Fig 26 and 27 show TCHAM for the 60second nominal baseline test (Test 112), and for the 240-second nominal long duration test (Test 127), respectively. It is apparent from the plots that near thermal steady state occurs rapidly (approximately 10 seconds after ignition), and that full thermal steady state was certainly achieved on Test 127 . Maximum temperatures on Test 112 occurred on TCHAM7A and TCHAM8A with respective values of $1900^{\circ} \mathrm{F}$ and $1860^{\circ} \mathrm{F}$. The maximum temperatures for Test 127 were not too different, being $1790^{\circ} \mathrm{F}$ and $1770{ }^{\circ} \mathrm{F}$ for TCHAM6C and TCHAM5A, respectively. These temperatures were very favorable for obtaining long life on coated columbium chambers. The corresponding injector face temperatures (TINF) for those same nominal-operating conditions were running around $260^{\circ} \mathrm{F}$.

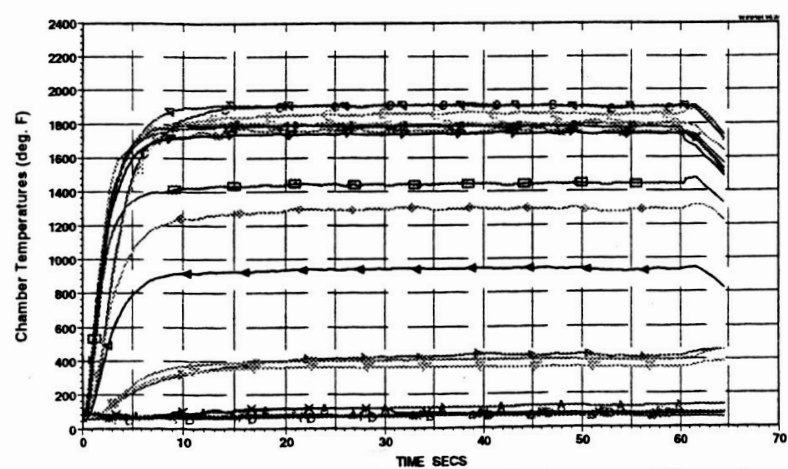

Figure 26. Primary Test 112 - Chamber Temperatures for $60 \mathrm{Sec}$ Test

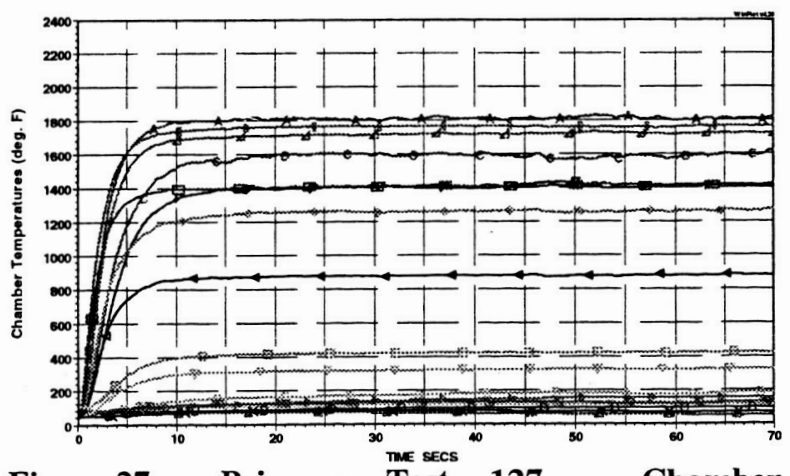

Figure 27. Primary Test 127 - Chamber Temperatures for 240 Sec Test

A single insulated chamber (Fig. 28) test was performed near the end of the primary test series to determine the increase in chamber temperatures due to the insulation. A post-test thermal analysis was performed on the primary temperature data, and the Aerojet predictive thermal code SCALE was calibrated from the inferred recovery temperatures and heat transfer coefficients. The results were plotted in Fig. 29a, showing that the SCALE code fits 
the temperature data well. A similar data fit from the Basic phase primary testing was added as Fig. 29b for comparison.

\section{Pulse Tests}

Pulse testing demonstrated some excellent engine response and pulse-to-pulse repeatability for EPW's down to 0.160 seconds (Pulse Train D). Pulse trains D$5 \%, \mathrm{D}-25 \%$ and $\mathrm{D}-50 \%$ are shown in Figure 30 for comparison. The lowest percent duty cycle, i.e., D-5\%, was the weakest looking pulse of the grouping, as it has the longest coast time between firings. The hardware does not get a chance to chill-in during this duty cycle. However, D-25\% was significantly better both in profile and in magnitude, and D-50\% was slightly better than that. Therefore, it is apparent that a cryogenic engine benefits from higher percentage duty cycles because the hardware is able to chill-in.

The next longest EPW was 0.320 seconds (Pulse Train E). Pulse trains E-15\%, E-25\% and E-50\% are shown in Figure 31 for comparison. This pulse train had a significantly better looking profile than the D-series, but it also showed improvement going from low to high on the percent duty cycle, as the engine operation begins to simulate a steady state firing. Longer EPW's continued the trend of improved profile and better magnitude, with the improved magnitude extending to lower percentage duty cycles as the EPW lengthened. The engine "liked" to operate at the 0.320-second EPW, as it represents a long enough on time for the fuel to be consumed so that there was not a lot of raw fuel spewing from the nozzle at shutdown, as in the case of the 0.080 second EPW.

Although the engine was fired at the 0.080 -second EPW for 2,425 total pulses in groupings as large as 800 pulses, it could not really develop full combustion within the 0.080 second EPW. Unburned fuel could be seen exiting the nozzle between pulses, and the lack of full combustion was audible when compared with the 0.320 second EPW where the sound was loud and distinct.

The engine also demonstrated the ability to operate successfully on two-phase flow. During Test 165, which was a pulse test of a 2.56-second EPW and a 5 percent duty cycle, the engine ignited on two-phase flow (340 psia and $260^{\circ} \mathrm{R}$ ) and crossed over the saturation line to liquid phase ( 340 psia and $183^{\circ} \mathrm{R}$ during the 2.56 second EPW. During the 48.6-second coast period, the hardware warmed sufficiently to cause two-phase flow at the beginning of the next EPW. Chamber pressure typically ranged from 88 to 140 psia over the 2.56-second EPW, reflecting transition from two-phase inlet conditions to liquid phase.

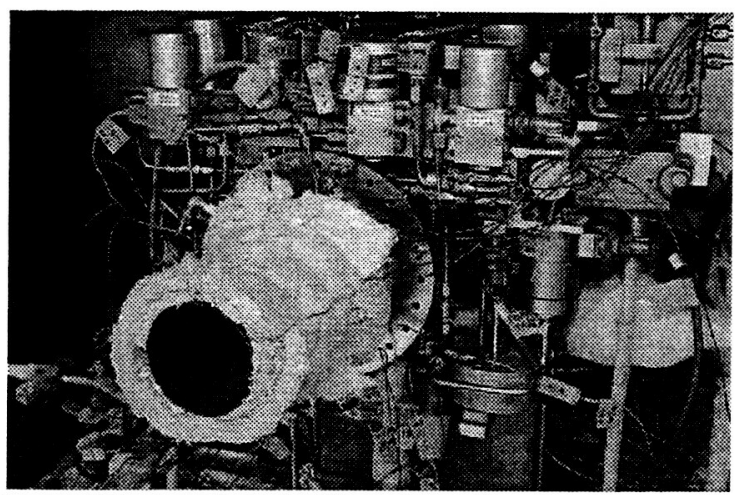

Figure 28. Insulated Chamber Configuration For Primary Test 169

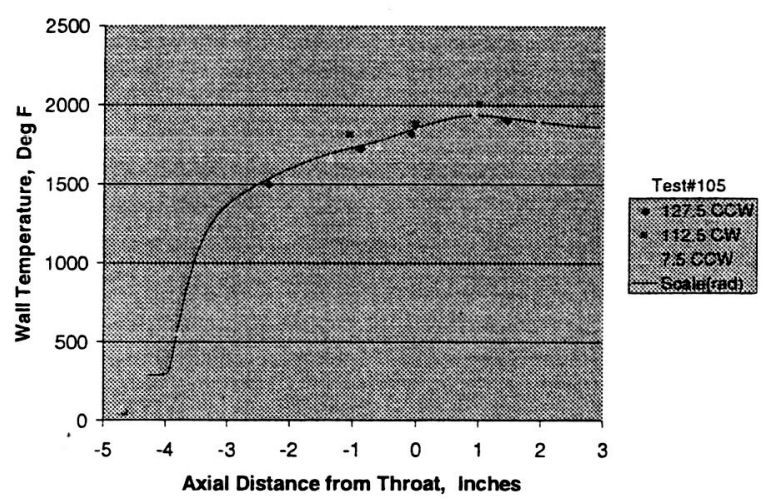

a)

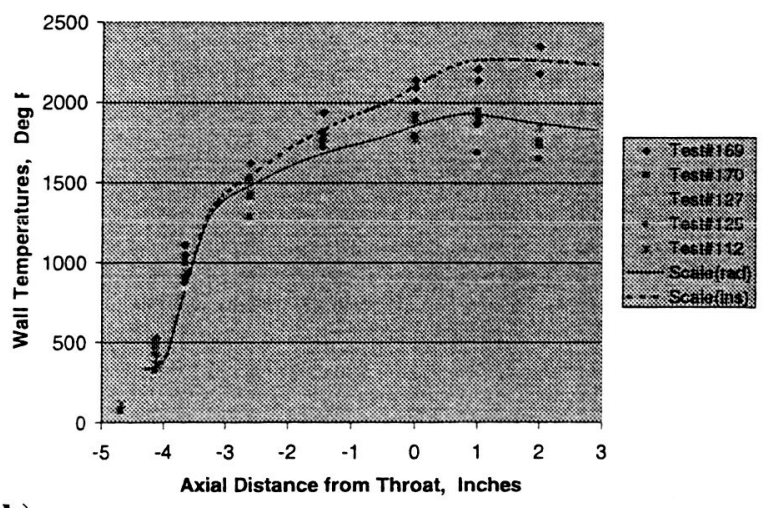

b)

Figure 29. Primary Test - Actual Temperature Comparison to SCALE Predictions 

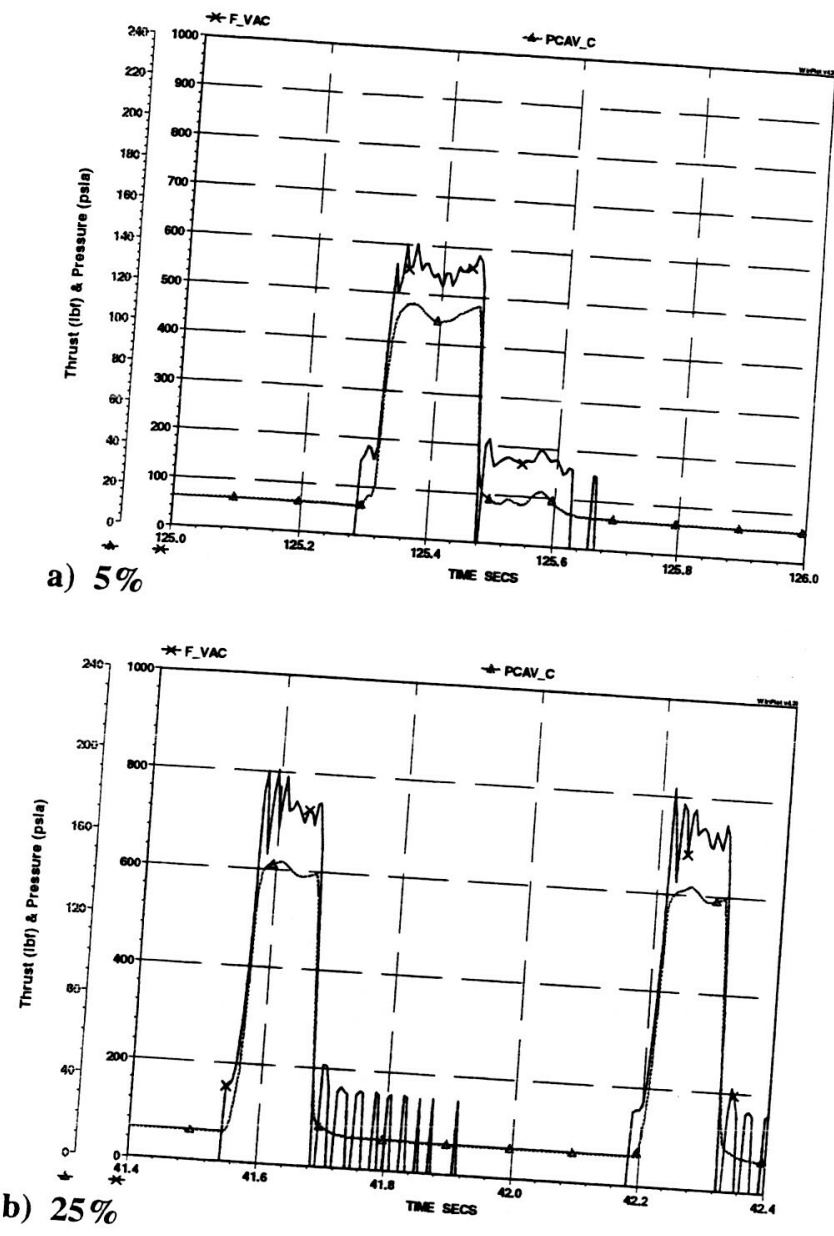

a) $15 \%$
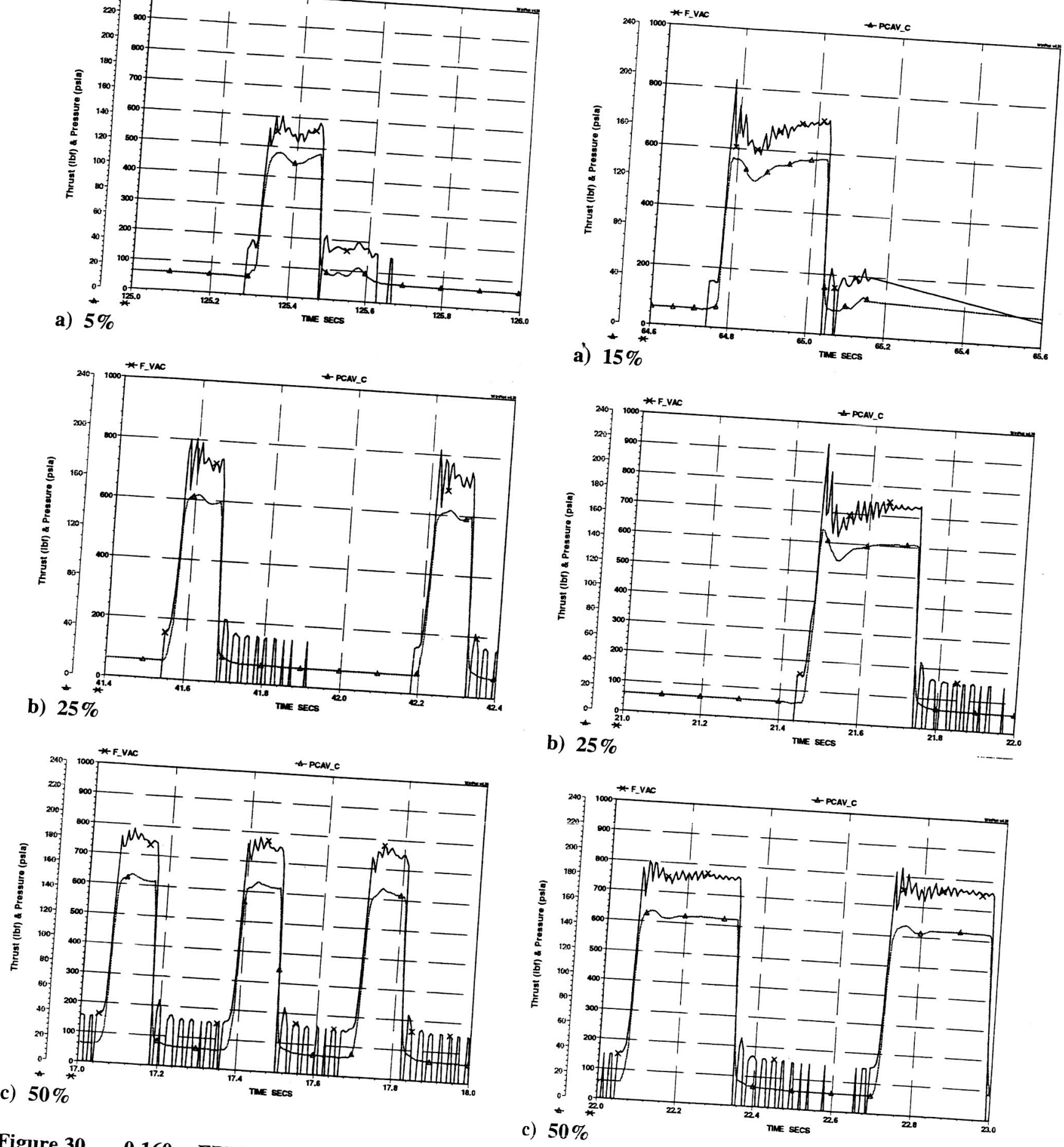

Figure 30.
0.160-s EPW at 5\%, 25\%, and 50\%
Duty Cycle

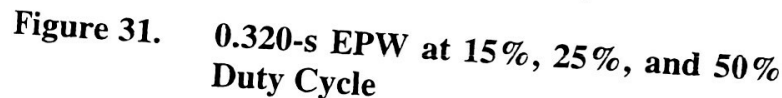




\section{Conclusions}

The test program conducted on the non-toxic dual thrust demonstration RCE was extremely successful. It showed that a relatively large $(870 \mathrm{lbf}$ ) cryogenic RCS engine can pulse as low 0.080 -second EPW, and perform all of the pulse trains planned for testing. The test effort also showed that a LOX igniter can reliably ignite the main engine and operate on liquid as well as two-phase oxygen in a very repeatable manner. In addition to the igniter, the engine also demonstrated robustness by operating in the two-phase region for LOX. Specific impulse in primary mode was very uniform across the Pc and MR values tested, and the extrapolated performance for a nozzle area ratio of 22:1 matches the current shuttle storable RCS engine values. Chamber temperatures were below $2000{ }^{\circ} \mathrm{F}$, enhancing long life for the coated columbium chamber.

Although the vernier testing produced some mixed results, particularly where pulsing was concerned in the full vernier configuration, some very good technical knowledge was gained that would aid future development. First of all, the engine ran at steady state for numerous times at durations of 240 and 320 seconds with very cool chamber temperatures. Igniter only mode showed how crisp and repeatable a small cryogenic thruster could be in pulse mode operation. It also showed that care must be exercised when selecting the thrust levels for a dual thrust design. Large thrust ratios, such as 34.8 for the $870 \mathrm{lbf} / 25 \mathrm{lbf}$ RCE do not lend themselves to the dual thrust concept. The current . demonstration engine would have benefited greatly had the vernier thrust level been double, i.e 50 lbf, as associated higher LOX flow rates would chill-in the vernier circuit more rapidly, and enable more vernier injector elements to incorporated into the design. Finally, dual thrust is a viable concept, and is potentially a useful design option for future flight vehicles.

\section{Acknowledgments}

The authors recognize it has taken a true team effort to accomplish all that has been done on the non-toxic dual thrust RCE program, and they recognize the team has transcended organizational boundaries. In that spirit, they wish to express gratitude and recognize the four constituent groups of the greater RCE team. First there is the NASA MSFC team consisting of principals Phil Best, Ron Unger, Chris Popp, Richard Sheller and David Sharp. Secondly, there is the NASA JSC team consisting of principals Eric Hurlburt and Tara Angstadt. Thirdly, there is the NASA WSTF team consisting of Bob Kowalski and Jennifer Allred. Finally, there is the Aerojet team with a number of support people, of whom the A-Zone test crew is paramount, as they have completed some truly amazing test programs. The A-Zone test crew consists of Charlie Carter, Mike Cooper, Rich Dudley, Grant Hart and Kevin Schneider.

\section{References}

1,"Nontoxic Orbiter Upgrade, Dual-Thruster Reaction Control Subsystem (RCS) Engine Test," White Sands Test Facility, Lyndon B Johnson Space Center, NASA WSTF-TR-0954-001-01, 11 April 2000.

${ }^{2}$ May, L., "Orbiter Nontoxic RCS Thrust Chamber Assembly Final Report," Final Test Report for Contract 9-NRA-96-BE-1, Aerojet, Sacramento, California, 8 September 1998.

${ }^{3}$ Robinson, P.J. and Veith, E.M., "Non-Toxic Dual Thrust Reaction Control Engine Development for On-Orbit APS Applications," AIAA-2003-9425, Aerojet Propulsion Division, Sacramento, California, July 2003.

${ }^{4}$ Rosenberg, S.D., Aitken, A.J., Jassowski, D.M., and Royer, K.F., "Ignition Systems for Space Shuttle Auxiliary Propulsion Systems," NASA CR-72890, Aerojet Liquid Rocket Company, Sacramento, California, 1972.

${ }^{5}$ Schoenman, L., "Hydrogen-Oxygen Auxiliary Propulsion for Space Shuttle," NASA CR120895, Aerojet Liquid Rocket Company, Sacramento, California, January 1973.

${ }^{6}$ Blubaugh, A.L. and Schoenman, L., "Extended Temperature Range ACPS Thruster Investigation," NASA CR-134655, Aerojet Liquid Rocket Company, Sacramento, California, August 1974.

${ }^{7}$ Lawver, B.R., Rousar, D.C., and Boyd, W.C., "Ignition Characterization of the GOX/Ethanol Propellant Combination," AIAA-84-1467, Aerojet TechSystems, Sacramento, California, August 1984.

${ }^{8}$ Nickerson, G.R., Coats, D.E., Dang, A.L., Dunn, S.S, and Kehtarnavaz, H., "Two Dimensional Kinetics (TDK) Nozzle Performance Computer Program," NAS 8-36863. 31 March 1989. 